\title{
Induction of a Cellular Defense Reaction Is Accompanied by an Increase in Sensory Neuron Excitability in Aplysia
}

\author{
Andrea L. Clatworthy, ${ }^{1}$ Gilbert A. Castro, ${ }^{1}$ Bernd U. Budelmann, ${ }^{2}$ and Edgar T. Walters ${ }^{1}$ \\ 'Department of Physiology and Cell Biology, University of Texas Medical School at Houston, Houston, Texas, 77225 and \\ 2Marine Biomedical Institute and Department of Otolaryngology, University of Texas Medical Branch, Galveston, Texas \\ 77555
}

\begin{abstract}
The complexity of vertebrate immune and nervous systems makes detailed cellular analysis of neuroimmune interactions a challenging prospect. The immune systems of invertebrates, although much less complex than their vertebrate counterparts, share basic cellular defense responses to wounded self or nonself. We have developed a simple model system to study neuroimmune interactions using an invertebrate preparation well suited to detailed cellular analysis. Loose ligation of peripheral nerves in Aplysia induced a cellular defense reaction evidenced by the accumulation of large numbers of amebocytes at the ligation site. From 5 to $\mathbf{3 0 ~} \mathrm{d}$ after ligation, the excitability of the soma of sensory neurons having axons in ligated nerves was increased compared to contralateral sensory neurons with axons in nonligated nerves. Spike threshold and afterhyperpolarization were reduced, and spike amplitude and duration were increased. Spike accommodation was also decreased such that sensory neurons on the ligated side fired more spikes to a $1 \mathrm{sec}$ intracellular depolarizing pulse than control sensory neurons. These effects are unlikely to be accounted for by ligation-induced injury of sensory axons since both morphological and electrophysiological evidence indicated that the axons in ligated nerves were healthy and able to conduct action potentials. Amebocytes activated by the presence of nonself may release factors that lead to a central sensitization of sensory neurons with axons in close proximity to the amebocytes.
\end{abstract}

[Key words: sensitization, excitability, amebocytes, injury, immune, nociceptor]

Bidirectional interactions between the immune and nervous systems are well documented in vertebrates (e.g., Castro, 1989; Tancredi et al., 1990; Myers et al., 1991). Unfortunately, these interactions are difficult to analyze at a mechanistic level because of the complexity of the systems involved. A useful approach is to develop simpler preparations that share fundamental mech-

Received July 28, 1993; revised Oct. 18, 1993; accepted Nov. 17, 1993.

We thank Dr. C. J. Bayne for assisting in the evaluation of the electron micrographs, M. S. Dobbins for expert technical assistance, $\mathrm{H}$. Alizadeh for providing preliminary pilot data, and J. Pastore for preparing the figures. This work was supported by National Science Foundation Grants BNS-901 1907 and IBN-9210268 to E.T.W. and the Initiative in Mucosal Biology, President's Office, The University of Texas Houston Health Science Center and Program Project Grant PO1-DK37260, NIDDKD,NIH to G.A.C.

Correspondence should be addressed to Andrea L. Clatworthy, Department of Physiology and Cell Biology, University of Texas Medical School at Houston, P.O. Box 20708, Houston, TX 77225.

Copyright (C) 1994 Society for Neuroscience $0270-6474 / 94 / 143263-08 \$ 05.00 / 0$ anisms with more complex systems. Invertebrate species are promising candidates for such an approach because they are often simpler, yet display basic cellular defensive responses to wounded self or nonself that are similar to those found in vertebrates, that is, an aggregation of cells at the target site and phagocytosis of foreign particles (Tripp, 1961; Prowse and Tait, 1969; Fisher and DiNuzzo, 1991). In mollusks, these immune responses involve granulocytic amebocytes, a class of blood cells that resemble polymorphonuclear leukocytes (PMNs) morphologically, and perform functions similar to some immune cells in mammals (LoVende et al., 1982; Bayne, 1983; Stefano et al., 1989a). While their role in anamnestic immune responses is questionable (Klein, 1989), molluscan amebocytes can distinguish self from nonself and are involved in chemotaxis, phagocytosis, and encapsulation (LoVende et al., 1982; Bayne, 1983).

Nlthough lacking an antibody based immune system, some degree of specificity is conferred on the invertebrate immune system by the presence of lectins-protein complexes with carbohydrate-specific binding properties that have the ability to agglutinate and opsonize nonself material. For example, Pauley et al. (1971) characterized factors in the hemolymph of the gastropod mollusk Aplysia californica capable of agglutinating marine bacteria and vertebrate red blood cells. Zipris and Gilboa-Garber (1987) reported that a lectin from Aplysia fasciata can stimulate human peripheral blood cells and can induce interleukin-2 production in stimulated $T$ cells. Interestingly, vertebrates have retained a family of nonimmunoglobulin, lectin-type recognition molecules - the pentraxins, of which C-reactive protein is a well-characterized example (Mold et al., 1982; Pepys, 1982). Therefore, fundamental principles underlying basic immune function may be common to invertebrate and vertebrate systems. This argument is strengthened by studies demonstrating that the immunocytes of the bivalve mollusk Mytilus edulis respond to interleukin- 1 and tumor necrosis factor in a manner similar to that of human granulocytes (Hughes et al., 1990).

One invertebrate that has been used extensively in studies of neural plasticity is the marine mollusk Aplysia californica. Recently its advantages as a model system to study injury-related plasticity have been exploited in intracellular studies of a centrally located population of nociceptive mechanosensory neurons - the VC cluster in the pleural ganglion (Walters et al., 1983; Walters, 1987; Clatworthy and Walters, 1993a,b). One of the most fundamental forms of nociceptive plasticity is the longterm increase in sensitivity that develops around a wound following injury (e.g., Woolf and Walters, 1991; Walters, 1994). This nociceptive sensitization protects a wound by triggering 


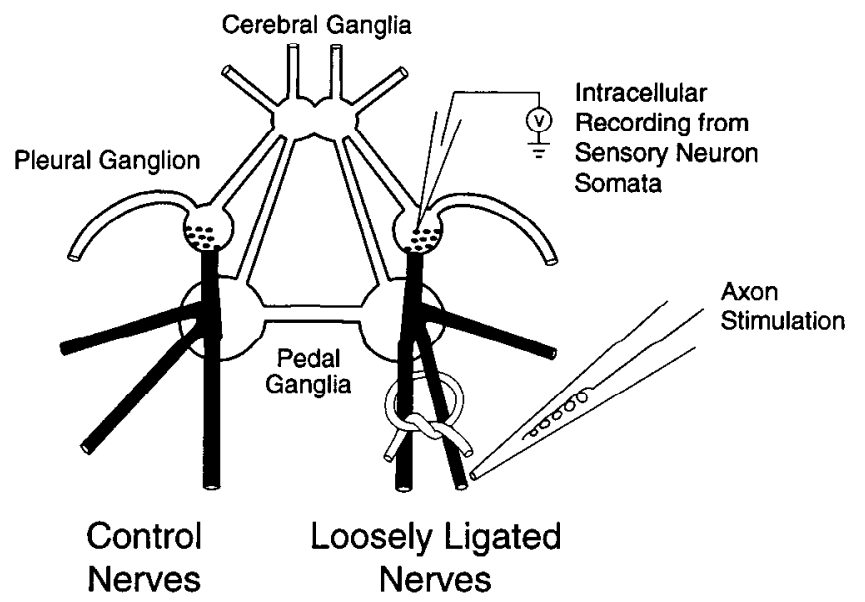

Figure 1. Diagram of in vitro preparation used to examine immune modulation of sensory excitability. A unilateral foreign body reaction was induced by loosely ligating nerves $\mathrm{p} 7, \mathrm{p} 8$, and $\mathrm{p} 9$ with a cotton strip on one side of the animal at a distance of approximately $1 \mathrm{~cm}$ from the pedal ganglion. The excitability of VC sensory neuron somata in the pleural ganglia (indicated by dots) having axons in these nerves (dark lines) was tested between 1 and $30 \mathrm{~d}$ later and compared to the excitability of contralateral VC sensory neurons having axons in nonligated nerves. The continued function of sensory axons in ligated nerves was tested at the end of each experiment by electrically stimulating nerve stumps distal to the ligated region while recording intracellularly from sensory somata in a region of the ganglion known to send axons to these nerves (Walters et al., 1983). The appearance of evoked spikes in the sensory neuron somata was taken as evidence for healthy axons.

brisker defensive responses to subsequent stimulation. In mammals, some sensitization signals are released by components of the immune system. For example, Levine et al. (1984, 1985) discovered that several potent chemoattractants for, and activators of, PMNs produce hyperalgesia in the rat that is dependent on PMNs, and Ferreira et al. (1988) showed that interleukin- $1 \beta$ is a potent hyperalgesic agent with a probable peripheral site of action.

Similarities in neuronal plasticity contributing to hypersensitivity at a wound site in mammals and Aplysia (Walters, 1987, 1994; Woolf and Walters, 1991) suggest that Aplysia may be a useful preparation in which to study fundamental aspects of nociceptor modulation by the immune system. Specifically, we asked whether the induction of a foreign body reaction near the axons of VC sensory neurons could alter the excitability of the sensory neuron soma. To induce a foreign body reaction, we loosely tied a narrow strip of cotton around the pedal nerves on one side of the animal. The pedal nerves innervating the other side of the body were not ligated and served as an internal control. We found that ligation of peripheral nerves induced a cellular defense reaction evidenced by the migration of large numbers of amebocytes to the ligation site. The excitability of sensory neurons with axons in close proximity to the amebocytes was increased, demonstrating that an immune reaction can modulate the signaling properties of identified neurons in Aplysia.

Some of these results have been presented in abstract form (Clatworthy and Walters, 1992, 1993c).

\section{Materials and Methods}

Subjects. Experiments were performed on Aplysia californica (150-300 $\mathrm{gm})$ supplied by Alacrity Marine Biological Services (Redondo Beach,
CA). Animals were maintained in artificial seawater (ASW) (Instant Ocean) at $17-19^{\circ} \mathrm{C}$ and fed romaine lettuce in quantities sufficient to maintain constant weight.

Experimental procedures. Surgery was performed after injection of ice-cold isotonic $\mathrm{MgCl}_{2}$ (30\% of the body volume) with the animal suspended in a chamber containing $0-1^{\circ} \mathrm{C} \mathrm{ASW}$. A small incision was made in the skin on the dorsal surface, exposing the pedal and pleural ganglia and pedal nerves $\mathrm{p} 9, \mathrm{p} 8$, and $\mathrm{p} 7$. A $1 \mathrm{~mm} \times 2 \mathrm{~cm}$ strip of unsterilized cotton gauze (Johnson \& Johnson) was tied very loosely around the pedal nerves innervating one side of the body at a distance of approximately $1 \mathrm{~cm}$ from the pedal ganglion (Fig. 1). It was important to ensure that the ligatures were very loose because axons in snugly ligated nerves are susceptible to injury (Alizadeh et al., 1990). The incision was sutured and the animal returned to its tank.

We performed two sets of control experiments. In one group of animals, a cotton strip was tied around the pedal nerves on both sides of the animal, and then the strip on one side was removed immediately (sham ligation). In a second control group, the pedal nerves on one side were sham ligated and the contralateral pedal nerves were not ligated.

Electrophysiological recordings. From 1 to $30 \mathrm{~d}$ after surgery animals were anesthetized with an injection of isotonic $\mathrm{MgCl}_{2}$ solution equivalent to approximately $50 \%$ of the body weight. The pedal-pleural ganglia and pedal nerves were dissected out of the animal and the pleural ganglia desheathed in a solution of saline containing equal volumes of isotonic $\mathrm{MgCl}_{2}$ solution and ASW. The isolated pedal-pleural preparation was then superfused at a constant rate with ASW for the duration of the experiment. Intracellular recordings were made from pleural VC sensory neurons, which send their axons out to the periphery via the ipsilateral pedal nerves (Fig 1; Walters et al., 1983). Recordings were made with glass capillary microelectrodes $(10-20 \mathrm{M} \Omega)$ filled with $3 \mathrm{M}$ potassium acetate. Sensory neurons were examined sequentially, alternating between right and left sides, and were paired by location in the ganglion.

Brief $(20 \mathrm{msec})$ intracellular depolarizing pulses were used to measure sensory spike threshold, amplitude, and afterhyperpolarization (see Walters et al., 1991). All measurements were taken on spikes that began after the offset of the depolarizing pulse. Two millisecond intracellular depolarizing pulses were used to measure spike duration, which was measured as the time from the peak of the spike to the first intersection of the voltage trace with the resting potential. Excitability was measured by counting the number of spikes fired in response to a $1 \mathrm{sec}$ intracellular depolarizing pulse at $1.25 \times$ and $2.5 \times$ the threshold determined with a $20 \mathrm{msec}$ pulse. Input resistance was monitored by measuring the change in potential elicited by injecting a $1 \mathrm{sec}, 0.5 \mathrm{nA}$ intracellular hyperpolarizing pulse. For statistical analysis, the values for all cells on each side were averaged, yielding a single score for each side in each animal. These averages were then compared across animals using a paired, twotailed $t$ test.

At the end of each experiment, spike conduction in the sensory axons running through ligated pedal nerves was tested to ensure they had not been damaged by the ligation procedure. Sensory neurons with axons in ncrves $\mathrm{p} 9, \mathrm{p} 8$, and $\mathrm{p} 7$ are readily found because they are localized to discrete regions of the VC cluster (Walters et al., 1983; E. T. Walters, unpublished observations). Nerve stumps were stimulated with $5 \mathrm{msec}$ current pulses several centimeters distal to the encapsulated region of the nerve while recording intracellularly from sensory cell bodies in the pleural ganglion.

Histology. In three randomly selected animals, nerve sections from control and ligated sides were examined. The section from the ligated side included the region where the cotton strip surrounded the nerve. The sections were pinned out in a Sylgard dish and fixed in 6\% glutaraldehyde buffered to $7.6 \mathrm{pH}$ with $0.2 \mathrm{M} \mathrm{Na}$ phosphate buffer for at least $24 \mathrm{hr}$ at $4^{\circ} \mathrm{C}$. After fixation, smaller sections were cut in $70 \%$ ethanol, subsequently dehydrated in graded ethanol solutions, and embedded individually in Epon 812 .

Light microscopy. For light microscopy, semithin cross sections (2 $\mu \mathrm{m})$ of the nerves were cut with a Diatome "Histoknife" on a LKB 8800 Ultratome III microtome. On the ligated side, the semithin sections were taken from the ligated region of the nerve. The sections were stained with toluidine blue, and viewed and photographed with an Olympus BH-2 or Zeiss Axiovert 35 microscope.

Transmission electron microscopy. Ultrathin cross sections (approximately $80 \mathrm{~nm}$ ) of the nerves were cut with a diamond knife on a LKB 8800 Ultratome III microtome. Sections were double stained (uranyl acetate, lead citrate) and viewed with a Jeol 100 CX or Phillips 301 transmission electron microscope. 
Table 1. Electrophysiological properties altered by loose ligation of pedal nerves

\begin{tabular}{lccccc} 
Property & Control & Ligated & $p$ & $\begin{array}{l}\text { Neu- } \\
\text { ron } \\
\text { pairs }\end{array}$ \\
\hline $\begin{array}{l}\text { Excitability at } 1.25 \times \text { threshold } \\
\quad \text { (number of spikes) }\end{array}$ & $1.19 \pm 0.03$ & $2.19 \pm 0.2$ & 0.0001 & 49 & 216 \\
$\begin{array}{l}\text { Excitability at } 2.5 \times \text { threshold } \\
\quad \text { (number of spikes) }\end{array}$ & $3.49 \pm 0.1$ & $5.91 \pm 0.4$ & 0.0001 & 45 & 195 \\
Threshold (nA) & $1.24 \pm 0.04$ & $1.00 \pm 0.03$ & 0.0001 & 49 & 216 \\
AHP (mV) & $4.22 \pm 0.11$ & $3.78 \pm 0.11$ & 0.0001 & 49 & 216 \\
Spike amplitude (mV) & $85.38 \pm 0.78$ & $89.21 \pm 0.86$ & 0.0001 & 49 & 216 \\
Spike duration (msec) & $3.86 \pm 0.14$ & $4.8 \pm 0.24$ & 0.0001 & 49 & 216 \\
Input resistance (MR) & $26.8 \pm 1.95$ & $34.1 \pm 2.1$ & 0.01 & 49 & 216 \\
Resting potential (mV) & $46.1 \pm 0.36$ & $45.87 \pm 0.39$ & 0.55 & 49 & 216 \\
\hline
\end{tabular}

Data are expressed as mean \pm SEM. Values of $p$ were determined with two-tailed paired $t$ tests. $n$, number of animals; AHP, afterhyperpolarization. Excitability refers to the number of spikes elicited by a 1 sec depolarizing pulse at $1.25 \times$ or $2.5 \times$ the 20 msec spike threshold.

\section{Results}

\section{Implantation of cotton string around the peripheral nerves induces a cellular defense reaction}

The cotton strip used to ligate pedal nerves on onc side of the animal became visibly encapsulated (to the naked eye) within $1 \mathrm{~d}$ of implantation. The capsule thickness progressively increased for at least a week after ligation. Cross sections of the ligated region of the pedal nerves taken $8 \mathrm{~d}$ after ligation and viewed at light and electron microscopic levels revealed a large increase in the number of amebocytes in the sheath surrounding the nerves compared to comparable sections through control nerves (Fig. 2). The amebocytes can be identified (1) by the more rounded and sometimes irregularly shaped nuclei (as compared to the more elongated sheath cell nuclei that are aligned parallel to the surface of the nerve sheath), (2) by an overall lighter appearance of the cytoplasm, and (3) by large, clear vesicles (probably phagosomes) that contain remnants of electrondense material (Fig. 2C,D). It can be seen that the tissue surrounding the ligated region of the nerve is less organized and that the density of amcbocytes is higher in the periphery of the nerve than close to the axons. These features are consistent with an aggregation of amebocytes coming from the hemocoel.

\section{Effects of foreign body implant on electrophysiological properties of the sensory neuron soma}

We ran a series of intracellular tests to determine whether unilateral loose ligation of pedal nerves changed the electrophysiological characteristics of pleural sensory cells with axons in ligated nerves (Table 1). The somata of sensory cells on the ligated side exhibited lower spike thresholds and smaller spike afterhyperpolarizations during intracellular stimulation with a $20 \mathrm{msec}$ depolarizing pulse than paired sensory cells on the nonligated (control) side (Fig. 3A). Sensory spike duration was also increased in sensory cells with axons in ligated nerves (Fig. $3 B$ ). A particularly interesting finding was that sensory spike amplitudes recorded from cells on the ligated side were larger than those recorded from cells on the control side (Fig. $3 A, B$ ).

Pleural sensory cells in Aplysia generally fire only a few spikes at the beginning of a prolonged intracellular depolarizing pulse. However, sensory cells having axons in ligated nerves were more excitable compared to control sensory cells (Fig. 4). Typically, control cells fired one spike to a $1 \mathrm{sec}$ depolarizing pulse at
$1.25 \times$ spike threshold and two to four spikes to the same test pulse at $2.5 \times$ spike threshold (Table 1 ). In contrast, cells with axons in ligated nerves fired approximately three spikes to the $1.25 \times$ threshold test pulse and six spikes to the $2.5 \times$ threshold pulse.

\section{Time course of hyperexcitability effect}

We used the excitability test at $2.5 \times$ spike threshold as our index of excitability to explore the time course of sensory neuron hyperexcitability. Figure 5 illustrates the mean differences in the number of spikes elicited by the 1 sec depolarizing test pulse in sensory neurons on ligated and control sides. Each point on the scatter plot represents the mean of the differences in spike number for five to eight pairs of sensory neurons per animal. There was little difference in the number of spikes evoked in sensory neurons on ligated and control sides between 1 and $4 \mathrm{~d}$ after nerve ligation. However, tests conducted $5 \mathrm{~d}$ or more after ligation revealed a consistent tendency for sensory cells on the ligated side to fire more spikes to the test pulse than sensory cells on the control side. This relative hyperexcitability on the ligated side appeared to decrease between 20 and $30 \mathrm{~d}$ after ligation.

\section{Effects of foreign body implant are not due to axonal injury or nerve stretch}

The increase in sensory excitability following the induction of a foreign body reaction in close proximity to sensory axons resembles sensory plasticily following axonal crush (Walters et al., 1991). It was important, therefore, to ensure that the observed plasticity was not a direct result of ligation-induced damage to the sensory axons. Both electrophysiological and morphological techniques were employed to test the viability of sensory axons in ligated nerves. First, at the end of each experiment we tested whether action potentials evoked by electrically stimulating nerves distal to the ligation could be conducted through the ligated region and recorded in the somata of sensory neurons having axons in stimulated nerves. Action potentials were recorded in $95 \%$ of the sensory neuron somata tested in the $\mathrm{p} 9$ region of the $\mathrm{VC}$ cluster on the ligated side.

Second, in three randomly selected animals we compared cross sections of nerves running through the ligated region with cross sections of contralateral nonligated nerves at the light and electron microscopic level (Fig. 2). Although the nerve sheath 

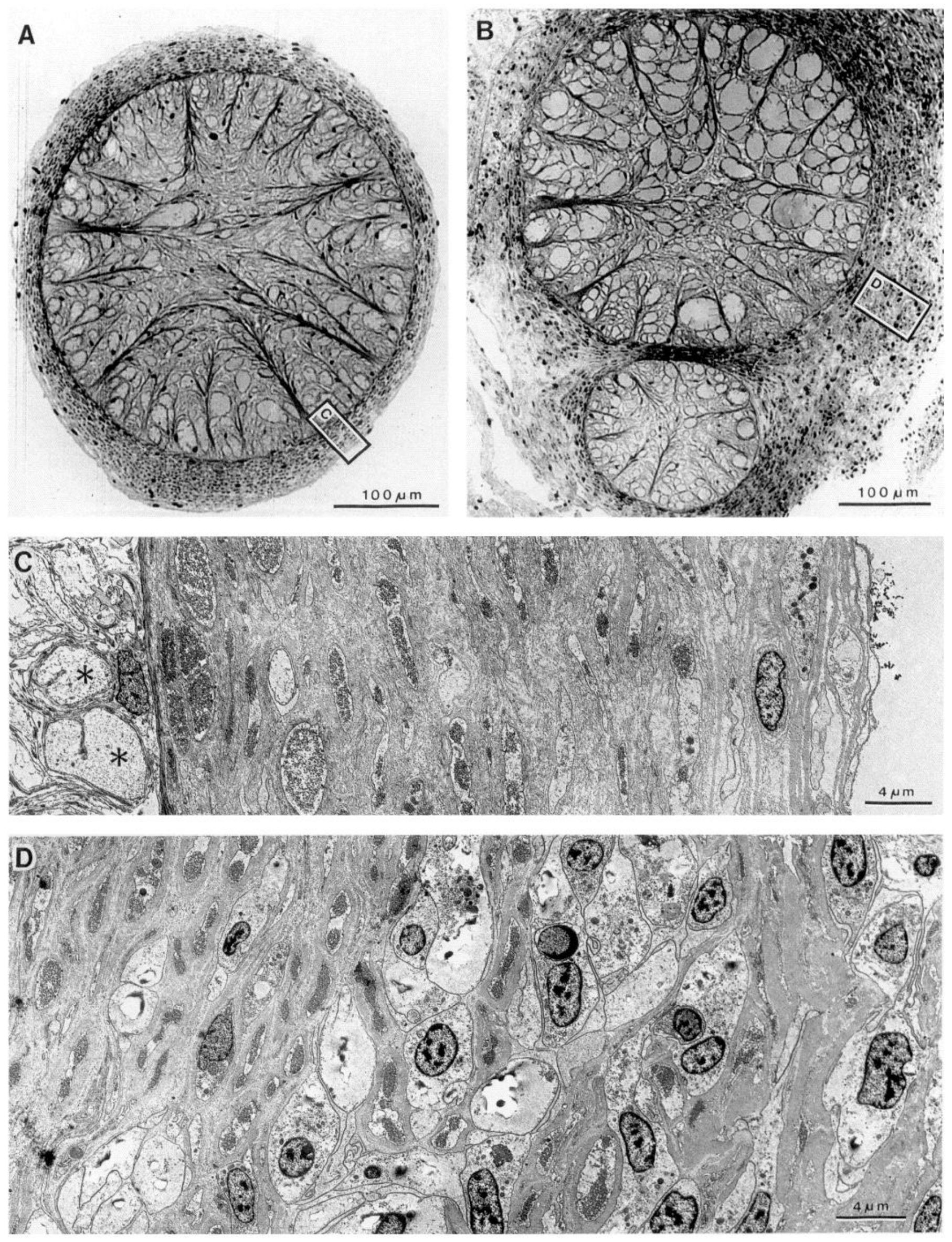
was altered by the encapsulation response (see above), there were no obvious differences at the light and electron microscopic levels in the structure of individual axons in control and ligated nerves.

When tying the cotton around the peripheral nerves, it was impossible to avoid some degrec of stretch of the nerves. To assess whether this nerve manipulation during the ligation procedure contributed to the sensory hyperexcitability, we performed two sets of control experiments in which the cotton gauze was tied around the nerves in the standard manner but was then immediately removed (sham ligation). Again we used the excitability test at $2.5 \times$ spike threshold. There was no significant difference in the number of spikes evoked in sensory neurons by the $1 \mathrm{sec}$ test pulse on sham-ligated and control sides of the animal (Fig. 6A). In contrast, sensory cells having axons in ligated nerves where the cotton remained in position for between 6 and $9 \mathrm{~d}$ fired significantly more spikes to the test pulse than contralateral sensory cells in the same animal having axons in sham-ligated nerves (Fig. 6B).

\section{Discussion}

The present experiments have demonstrated that a cellular defense response induced by implanting a loose cotton ligature around peripheral nerves in Aplysia is accompanied by an enhancement of the excitability of VC sensory neurons having axons in the ligated nerves. This effect is qualitatively similar to the sensory plasticity that follows axonal injury in these same neurons (Walters et al., 1991). The increase in central excitability of the sensory neuron would be expected to increase the likelihood of central afterdischarge to cutaneous stimuli (Clatworthy and Walters, 1993a), while the increase in spike duration would be expected to both enhance spike propagation through regions of the neuron having a low safety factor for conduction (Clatworthy and Walters, 1993a) and contribute to synaptic facilitation if the spike broadening occurs in presynaptic terminals (e.g., Klein and Kandel, 1978; Hochner et al., 1986; Blumenfeld et al., 1990). We do not yet know the conductance alterations that underlie long-term sensory neuron hyperexcitability after nerve ligation, but it will be interesting to see if these alterations involve persistent depression of the same $\mathrm{K}^{+}$currents that have been shown to be depressed in Aplysia sensory neurons for much shorter periods of time following 5-HT application or cutaneous shock. These include (1) the S-type $\mathrm{K}^{+}$current, which is partially active at resting potential (e.g., Klein et al., 1982; Scholz and Byrne, 1987; Baxter and Byrne, 1989); (2) a transient, steeply voltage-dependent "delayed-rectifier" $\mathrm{K}^{+}$current (Baxter and Byrne, 1989; Goldsmith and Abrams, 1992; Hochner and Kandel, 1992); and (3) a steadystate $\mathrm{Ca}^{2+}$-activated $\mathrm{K}^{+}$current (Walsh and Byrne, 1989).

An earlier study found that hyperexcitability of VC sensory neurons following a tighter ligation procedure was associated with axonal damage (Alizadeh et al., 1990, and unpublished

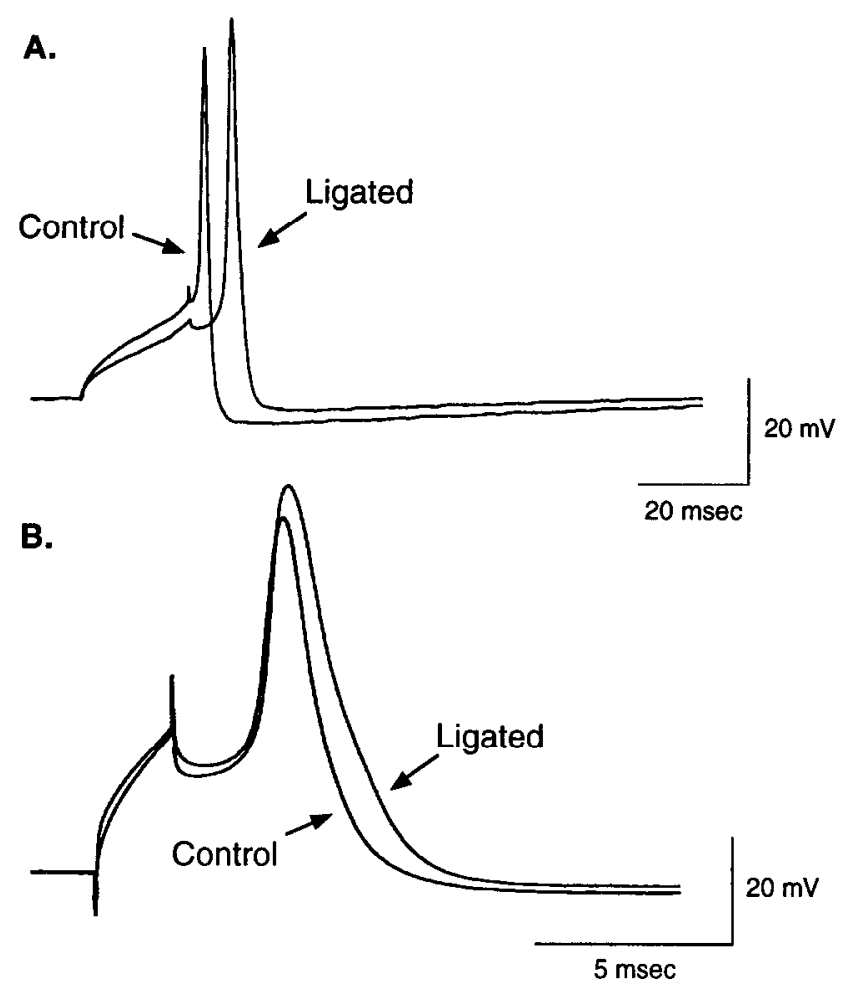

Figure 3. Examples of long-term electrophysiological changes in sensory neuron somata associated with loose ligation of pedal nerves containing their axons. The ligation remained in position around the nerves for $9 \mathrm{~d}$ before testing. $A$, Response of a sensory neuron having its axon in a ligated nerve and a control sensory neuron having its axon in a nonligatcd ncrve to a $20 \mathrm{msec}$ intracellular depolarizing pulse. Note the smaller afterhyperpolarization and the larger spike amplitude of the neuron on the ligated side. $B$, Expanded record to show the prolonged duration of the action potential recorded from the sensory neuron on the ligated side. Spikes illustrated in this and subsequent figures are attenuated because of the limited sampling rate of the data acquisition system.

observations). However, the present results are unlikely to be accounted for by axonal damage for several reasons. First, action potentials evoked by nerve stimulation distal to the ligation were recorded in almost all sensory neuron somata tested in the appropriate region within the VC cluster, suggesting that their axons were uninjured at the time of testing. Second, histological examination of nerve sections through the ligated region revealed no obvious axonal damage. Third, the latency to onset of the soma hyperexcitability following ligation was approximately $5 \mathrm{~d}$. This contrasts with the shorter latency (2-3 d) of sensory neuron plasticity induced by crushing the same region of the pedal nerves (Walters et al., 1991). Fourth, a difference was found between the effects of loose ligation and axotomy. The amplitude of the spikes evoked by intracellular stimulation

Figure 2. Light $(A, B)$ and electron microscopic $(C, D)$ views of cross sections of control $(A, C)$ and ligated $(B, D)$ pedal nerves of $A p l y s i a 8 \mathrm{~d}$ after unilateral implantation of a cotton strip. Note the increase in thickness of the nerve sheath in the ligated region of the nerve $(B)$, due to the accumulation of amebocytes. The boxed areas in $A$ and $B$ show the approximate locations from which the higher-power electron micrographs $C$ and $D$ were taken. In the periphery of the sheath surrounding the ligated nerve, many rounded, sometimes irregularly shaped nuclei with electrondense chromatin can be seen (right two-thirds of $D$ ), whereas only a few amebocytes occur in the sheath close to the axons (left third of $D$ ). In the control nerve $(C)$, only one elongated nucleus (presumably of a sheath cell) is seen close to the periphery (far right) of the nerve sheath. Near the left edge are two cross sections of axons $\left({ }^{*}\right)$ with their characteristic membrane infoldings. No obvious differences were found in the structure of individual axons in control $(A)$, and ligated $(B)$ nerves. 

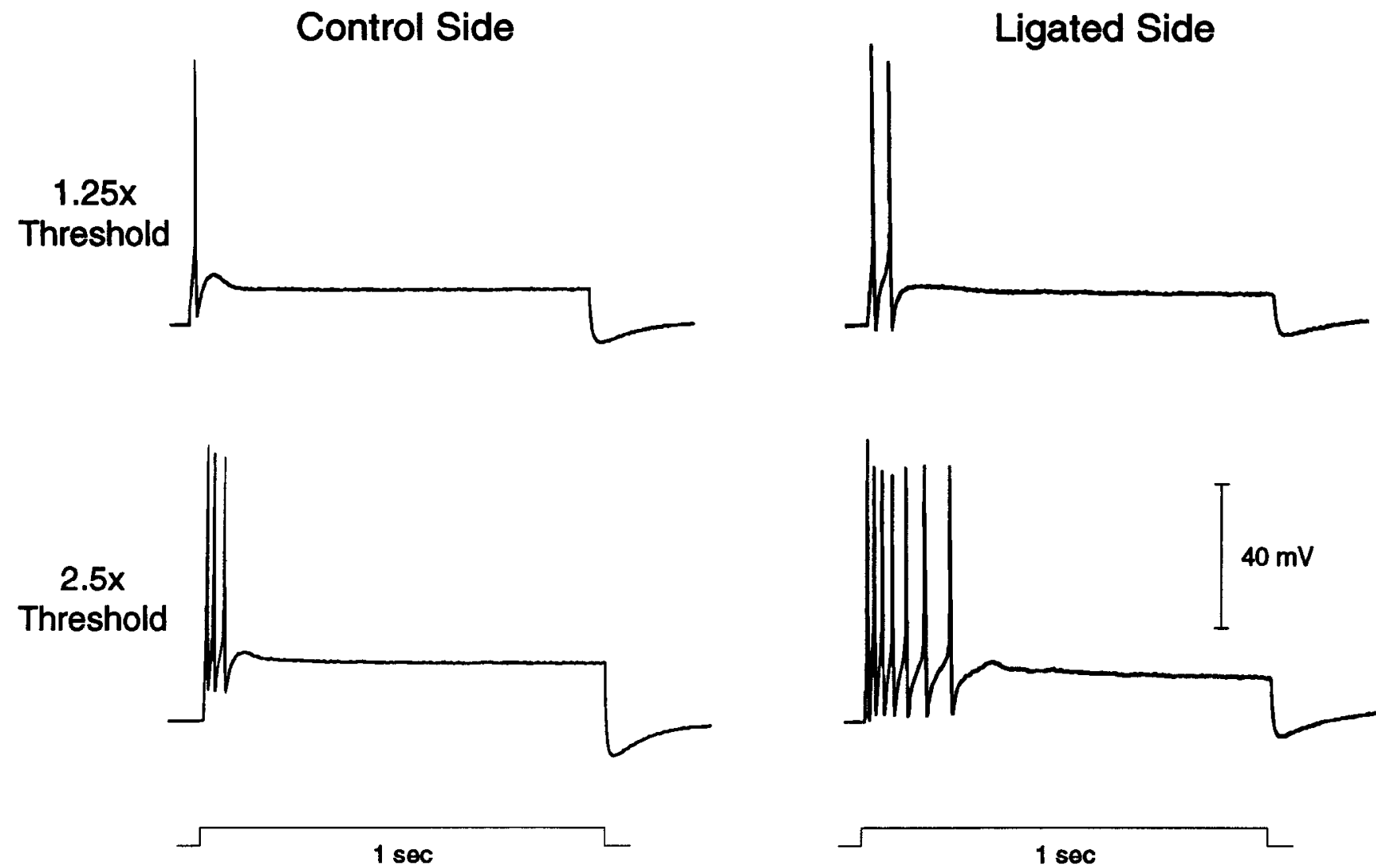

Figure 4. Increase in excitability of a sensory neuron having its axon in a ligated nerve compared to a sensory neuron with its axon in a nonligated nerve. Each cell was tested with a $1 \mathrm{sec}$ intracellular depolarizing pulse at $1.25 \times$ and $2.5 \times$ the $20 \mathrm{msec}$ threshold.

on the ligated side was greater than the amplitude of spikes recorded in control neurons. This effect was not seen after nerve crush (Walters et al., 1991; A. L. Clatworthy, M. F. Dulin, and E. T. Walters, unpublished observations). Indeed, to our knowledge, this is the first documentation of an increase in spike amplitude associated with plasticity of Aplysia sensory neurons. Fifth, transient perturbations associated with the ligation procedure such as stretch of the nerves were not responsible for the

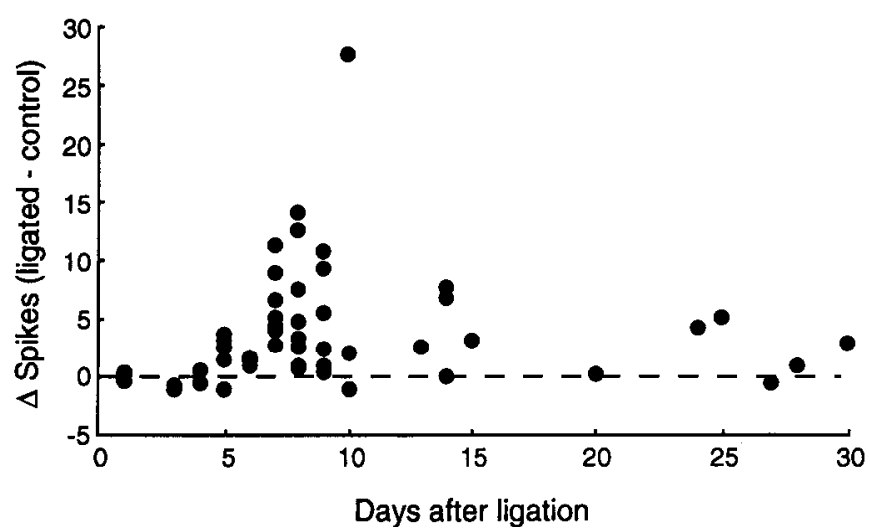

Figure 5. Time course of sensory hyperexcitability. Each point on the scatter plot represents the mean of the differences in the number of spikes evoked by a $1 \mathrm{sec}$ depolarizing test pulse $(2.5 \times$ threshold $)$ for four to eight sensory neuron pairs per animal. Five days or more after ligation there was a consistent tendency for sensory neurons on the ligated side to fire more spikes to the test pulse than control sensory neurons. effects since hyperexcitability was not produced in sensory neurons with axons in sham-ligated nerves. Although we have excluded the possibility that mechanical effects at the time of tying the ligature around the peripheral nerves contributed to the sensory hyperexcitability, we cannot completely rule out the possibility that more subtle physical effects resulting from chronic exposure of the nerve to the ligature (e.g., weak mechanical irritation) may have contributed to the increase in sensory ex-
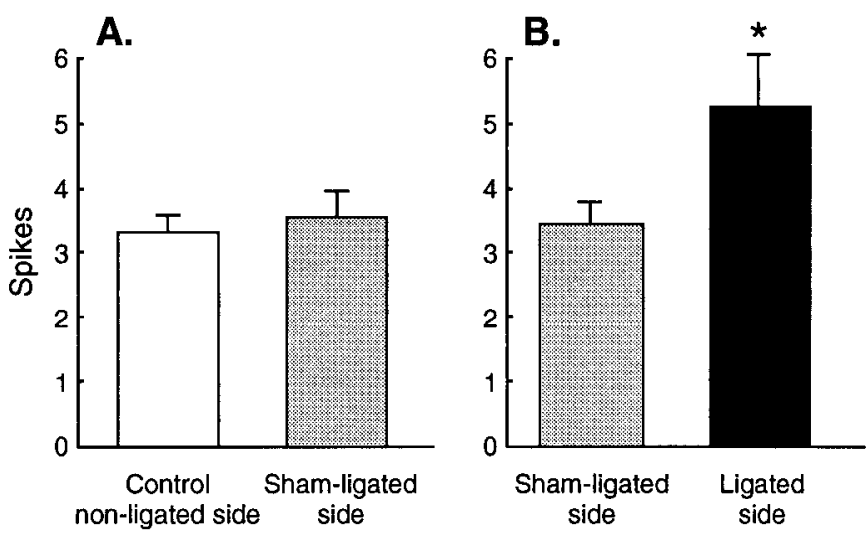

Figure 6. Lack of effect of brief nerve manipulations on sensory hyperexcitability. $A$, Lack of significant difference in the number of spikes evoked by a 1 sec depolarizing pulse on sham-ligated and nonligated sides of the animal $(n=6)$. $B$, Difference in the number of spikes evoked by this same test pulse on sham-ligated and ligated sides of the animal $(n=6)$. Data presented as mean and SEM. ${ }^{*}, p<0.05$ 
citability. However, similar effects on sensory neuron excitability were produced in preliminary experiments by damaging the sheath (without causing any obvious damage to the underlying axons). Since molluscan amebocytes are attracted to wounded-self (Stefano et al., 1989a), this procedure is likely to have caused an accumulation of amebocytes in close proximity to sensory axons in the absence of any chronic mechanical irritation of the nerve. Other potential signals could be relcascd from injured sheath cells. Conclusive analysis of the relative contributions of potential mechanical and chemical contributions to the effects of foreign body reactions on sensory neuron excitability will be undertaken using cell culture methods.

Since the present results cannot be accounted for by axonal injury, and appear not to be related to chronic mechanical irritation of the nerve, we conclude that the signals that initiate the sensory changes associated with the implantation of a foreign body may be mediated by components of the foreign body reaction. Amebocytes activated by the presence of nonself may release factors, perhaps cytokines, that initiate the excitability changes recorded in sensory neurons with axons in close proximity to the amebocytes.

In a more natural setting, a foreign body reaction could be induced by the entry of pathogens or parasites through a wound. The entry of foreign organisms could trigger the host cellular defense system to release a variety of paracrine substances, some of which might influence components of the nervous system in close proximity to the foreign bodies. In particular, factors released from the immune system may provide signals of tissue damage that are used to induce sensitization around a wound. The importance of neuroimmune interactions in mollusks is indicated by the ability of the parasite Trichubilharzia ocellata to modulate indirectly the activity of the hemocytes of its snail host Lymnaea stagnalis by inducing the CNS of the snail to release a factor that suppresses the snail's own hemocytes (Amen and De Jong-Brink, 1992). The finding that severing a peripheral nerve in the bivalve mollusk Mytilus evokes a cellular defense response that involves the directed migration and adherence of amebocytes to the cut end of the nerve (Stefano et al., 1989a) raises the interesting possibility that some of the previously described long-term effects of nerve crush on sensory excitability (Walters et al., 1991) are due to signals released from amebocytes. It will be interesting to examine nerve crush sites in Aplysia to see if amebocytes are indeed attracted to these areas. Given the regeneration of sensory axons in Aplysia that occurs after pedal nerve crush (Steffensen and Morris, 1992; Dulin and Walters, 1993), it is of particular interest that the induction of an inflammatory reaction in rat dorsal root ganglia enhances regeneration of previously crushed axons in the associated dorsal root (Lu and Richardson, 1991).

General similarities between our results and those demonstrating that intestinal myenteric and autonomic neurons in the cervical ganglion of guinea pigs respond to paracrines released from mast cells (Weinreich and Undem, 1987; Wood, 1991) suggest that commonalities exist between neuroimmune interactions in mollusks and mammals. If this is indeed the case, our finding that the induction of a foreign body response can modulate the excitability of a nociceptive system in Aplysia has interesting implications for the involvement of the immune system in some chronic pain states that occur in mammals when peripheral somatic nerves are damaged. In particular, sensory disorders (hyperalgesia and allodynia) similar to those accompanying peripheral neuropathies in humans are produced by ligating peripheral nerves in rats (Bennett and Xie, 1988). Although ligation does produce some loss of sensory axons in this model, there appears to be no correlation between the extent of fiber loss and the degree of hyperalgesia (Carlton et al., 1991; Maves et al., 1993). Indeed, Maves et al. (1993) have shown that merely laying chromic gut adjacent to the sciatic nerve produces hyperalgesia. Based on our findings in Aplysia, one might speculate that ligation of the rat peripheral nerve induces a foreign body reaction, and that factors released from immune cells mediating the inflammatory response modulate the excitability of sensory neurons with axons in ligated nerves. The failure of some ligature materials to induce hyperalgesia in this model (Maves et al., 1993) may be related to their inability to induce an immune reaction of sufficient magnitude to influence sensory excitability.

Potential similarities between neuronal alterations induced by local immune reactions in Aplysia and mammals suggest that it will be interesting to compare further the effects of immune reactions on sensory function in a wide variety of species and physiological systems.

\section{References}

Alizadeh H, Clatworthy AL, Castro GA, Walters ET (1990) Induction of an immune reaction in Aplysia is accompanied by long-term enhancement of sensory neuron excitability. Soc Neurosci Abstr 16 : 597.

Amen RI, De Jong-Brink M (1992) Trichobilharzia ocellata infections in its snail host Lymnaea stagnalis: an in vitro study showing direct and indirect effects on the snail internal defense system via the host central nervous system. Parasitology 105:409-416.

Baxter DA, Byrne JH (1989) Serotonergic modulation of two potassium currents in the pleural sensory neurons of Aplysia. J Neurophysiol 62:665-679.

Bayne CJ (1983) Molluscan immunobiology. In: The mollusca, Vol 5 , Physiology 2 (Saleuddin ASM, Wilbur KM, eds), pp 407-486. New York: Academic.

Bennett GJ, Xie YX (1988) A peripheral mononeuropathy in rat that produces disorders of pain sensation like those seen in man. Pain 33: 87-107.

Blumenfeld H, Spira ME, Kandel ER, Siegelbaum SA (1990) Facilitatory and inhibitory transmitters modulate calcium influx during action potentials in Aplysia sensory neurons. Neuron 5:487-499.

Carlton SM, Dougherty PM, Pover CM, Coggeshall RE (1991) Neuroma formation and numbers of axons in a rat model of experimental peripheral neuropathy. Neurosci Lett 131:88-92.

Castro GA (1989) Intestinal neuroimmune interactions. In: Falk symposium no. 50, Nerves and the gastrointestinal tract (Singer MV, Goebell H, eds), pp 287-297. Lancaster: MTP.

Clatworthy AL, Walters ET (1992) Long-term increase in action potential amplitude and soma excitability in Aplysia sensory neurons following periaxonal immune reaction. Soc Neurosci Abstr 18:595.

Clatworthy AL, Walters ET (1993a) Rapid amplification and facilitation of mechanosensory discharge in Aplysia by noxious stimulation. J Neurophysiol 70:1181-1194.

Clatworthy AL, Walters ET (1993b) Activity-dependent depression of mechanosensory discharge and excitability in Aplysia. $\mathrm{J}$ Neurophysiol 70:1195-1209.

Clatworthy AL, Walters ET (1993c) Loose ligation of Aplysia nerve induces aggregation of presumptive immunocytes during sensory hyperexcitability. Soc Neurosci Abstr 19:98.

Dulin MF, Walters ET (1993) Similar alterations of sensory and motor neurons in Aplysia persist after regeneration. Soc Neurosci Abstr 19: 578.

Ferreira SH, Lorenzetti BB, Bristow AF, Poole S (1988) Interleukin-1 beta as a potent hyperalgesic agent antagonized by a tripeptide analogue. Nature 334:698-700.

Fisher WS, DiNuzzo AR (1991) Agglutination of bacteria and erythrocytes by serum from six species of marine molluscs. J Invert Pathol 57:380-394.

Goldsmith BA, Abrams TW (1992) cAMP modulates multiple $\mathrm{K}^{+}$ 
currents, increasing spike duration and excitability in Aplysia sensory neurons. Proc Natl Acad Sci USA 89:11481-11485.

Hochner B, Kandel ER (1992) Modulation of transient $\mathrm{K}^{+}$current in pleural sensory neurons of Aplysia by serotonin and cAMP: implications for spike broadening. Proc Natl Acad Sci USA 89:1147611480 .

Hochner B, Klein M, Schacher S, Kandel ER (1986) Action potential duration and the modulation of transmitter release from sensory neurons of Aplysia in presynaptic facilitation and behavioral sensitization. Proc Natl Acad Sci USA 83:8410-8414.

Hughes TK, Smith EM, Cadet P, Sinisterra J, Leung MK, Shipp MA, Scharrer B, Stefano GB (1990) Interaction of immunoactive monokines (IL-I and TNF) in the bivalve mollusc Mytilus edulis. Proc Natl Acad Sci USA 87:4426-4429.

Klein J (1989) Are invertebrates capable of anticipatory immune re sponses? Scand J Immunol 29:499-505.

Klein M, Kandel ER (1978) Presynaptic modulation of voltage-dependent $\mathrm{Ca}^{2}{ }^{2}$ current: mechanism for behavioral sensitization in Aplysia californica. Proc Natl Acad Sci USA 75:3512-3516.

Klein M, Camarado J, Kandel ER (1982) Serotonin modulates a specific potassium current in the sensory neurons that show presynaptic facilitation in Aplysia. Proc Natl Acad Sci USA 79:5713-5717.

Levine JD, Lau W, Kwiat G, Goetzl EJ (1984) Leukotriene B 4 produces hyperalgesia that is dependent on polymorphonuclear leukocytes. Science 225:743-745.

Levine JD, Gooding J, Donatoni P, Borden L, Goetzl E.J (1985) The role of polymorphonuclear leukocyte in hyperalgesia. $\mathrm{J}$ Neurosci 5:3025-3029.

LoVende PT, Gherson J, Richards SS (1982) Amebocyte accumulation in Biomphalasia glabrata. Fine structure. Dev Comp Immunol $6: 441-449$.

Lu X, Richardson PM (1991) Inflammation neat the nerve cell body enhances axonal regeneration. J Neurosci 11:972-978.

Maves TJ, Pechman PS, Gebhart GF, Meller ST (1993) Is constrictive nerve injury in the rat required to produce disorders of pain sensation like those seen in man? Pain 54:57-69.

Mold C, DuClos TW, Nakayama S, Edwards KM, Gewurz H (1982) C-reactive protein reactivity with complement and effects on phagocytosis. Ann NY Acad Sci 389:251-262.

Myers AC, Undem BJ, Weinreich D (1991) Influence of antigen on membrane properties of guinea pig bronchial ganglion neurons. J Appl Physiol 71:970-976.

Pauley GB, Granger BA, Krassner SM (1971) Characterization of a natural agglutinin present in the hemolymph of the California sea hare Aplysia californica. J Invert Pathol 18:207-218.

Pepys MB (1982) C-Reactive protein and the acute phase response. Immunol Today 3:28.
Prowse RH, Tait NN (1969) In vitro phagocytosis by amoebocytes from the haemolymph of Helix aspersa (Muller). I. Evidence for opsonic factor(s) in serum. Immunology 17:437-443.

Scholz KP, Byrne JH (1987) Long-term sensitization in Aplysia: biophysical correlates in tail sensory neurons. Science 235:685-687.

Stefano GB, Leung MK, Zhao X, Scharrer B (1989a) Evidence for the involvement of opioid neuropeptides in the adherence and migration of immunocompetent invertebrate hemocytes. Proc Natl Acad Sci USA 86:626-630.

Stefano GB, Zhao X, Bailey D, Metlay M, Leung MK (1989b) High affinity dopamine binding to mouse thymocytes and Mytilus edulis (Bivalvia) hemocytes. J Neuroimmunol 21:67-74.

Steffensen I, Morris CE (1992) Recovery of tail mechanosensory function in Aplysia following crush of nerve p9. Soc Neurosci Abstr 18: 531 .

Tancredi V, Zona C, Velotti F, Eusebi F, Santoni A (1990) Interleukin-2 suppresses established long-term potentiation and inhibits its induction in rat hypothalamus. Brain Res 52:149-151.

Tripp MR (1961) The fate of foreign materials experimentally introduced into the snail Australorbis glabratus. J Parisitol 47:745-751.

Walsh JP, Byrne JH (1989) Modulation of steady-state $\mathrm{Ca}^{2+}$ activated $\mathrm{K}^{+}$current in tail sensory neurons of Aplysia role of serotonin and cAMP. J Neurophysiol 61:32-44.

Walters ET (1987) Multiple sensory neuronal correlates of site-specific sensitization in Aplysia. J Neurosci 7:408-417.

Walters ET (1994) Injury-related hehavior and neuronal plasticity: an evolutionary perspective on sensitization, hyperalgesia, and analgesia. Int Rev Neurobiol, in press.

Walters ET, Byrne JH, Carew TJ, Kandel ER (1983) Mechanoafferent neurons innervating the tail of Aplysia. I. Response properties and synaptic connections. J Neurophysiol 50:1522-1542.

Walters ET, Alizadeh H, Castro GA (1991) Similar neuronal alterdtions induced by axonal injury and learning in Aplysia. Science 253: 797-799.

Weinreich D, Undem BJ (1987) Regulation of synaptic transmission in isolated guinea pig autonomic ganglia. J Clin Invest 79:1529-1532.

Wood JD (1991) Communication between mini-brain in gut and the enteric immune system. News Physiol Sci 6:64-69.

Woolf CJ, Walters ET (1991) Common patterns of plasticity contributing to nociceptive sensitization in mammals and Aplysia. Trends Neurosci 14:74-78.

Zipris D, Gilboa-Garber N (1987) Stimulation of human peripheral lymphocytes and induction of interleukin-2 production by a lectin from the gonad of the sea hare, Aplysia fasciata. Dev Comp Immunol $11: 501-511$. 